\title{
Article \\ Seismic Damage Probability Assessment of Isolated Girder Bridges Based on Performance under Near-Field Earthquakes
}

\author{
Qiang Liu*(1) and Chunyan Yang \\ College of Harbour and Coastal Engineering, Jimei University, Xiamen 361021, China; ycy@jmu.edu.cn \\ * Correspondence: Liutanq007@aliyun.com; Tel.: +86-130-0391-0928
}

check for updates

Citation: Liu, Q.; Yang, C. Seismic Damage Probability Assessment of Isolated Girder Bridges Based on Performance under Near-Field Earthquakes. Appl. Sci. 2021, 11, 9595 https://doi.org/10.3390/ app11209595

Academic Editor: Maria Favvata

Received: 23 September 2021

Accepted: 10 October 2021

Published: 14 October 2021

Publisher's Note: MDPI stays neutral with regard to jurisdictional claims in published maps and institutional affiliations.

Copyright: (c) 2021 by the authors. Licensee MDPI, Basel, Switzerland. This article is an open access article distributed under the terms and conditions of the Creative Commons Attribution (CC BY) license (https:/ / creativecommons.org/licenses/by/ $4.0 /)$.

\begin{abstract}
This paper presents a copula technique for developing seismic fragility curves for an RC (reinforced concrete) isolated continuous girder bridge, by considering earthquake damage indicators such as bridge piers, isolated bearing components, and the main girder of collision damage. The results of this method are compared with those of the limit method of the first-order reliability theory. Meanwhile, the incremental dynamic analysis of the bridge structure under different failure conditions is carried out, and the randomness of the near-fault ground motion and the structural parameters are accounted. Based on the damage index of the isolated bridge under different damage conditions, the seismic fragility curves of each component and the whole isolated bridge are obtained. The research shows that the safety control of the isolated continuous girder bridge structure is mainly affected by the seismic fragility of the isolated bearing, the influence of bridge pier seismic fragility is relatively small, and the probability of beam collision in an isolated bridge is lower than that of a general bridge without isolation bearing. By applying the isolation scheme, the probability of different damage state of the bridge structure is greatly reduced, thus the seismic performance is improved. It also verifies the efficiency and superiority of copula technology. The results will provide a reference for future seismic damage prediction.
\end{abstract}

Keywords: RC isolated continuous girder bridge; the copula function; seismic fragility analysis; near-fault ground motions; damage index

\section{Introduction}

The bridge is an important hub of transportation systems, especially the reinforced concrete long-span continuous girder bridge, the most common type on highways in China. In recent years, it has been noticed that the long-period velocity and displacement pulse motion of the near-fault ground motion may adversely affect the seismic performance and design of the bridge [1-4]. All previous earthquake disaster statistics have shown that these bridges will sustain serious damage from earthquakes $[5,6]$. In order to effectively reduce the seismic damage to bridges, the isolation design of lead rubber bearing (LRB) is used in the actual engineering. The seismic responses of such isolated structures have already been widely investigated $[7,8]$. It was found that this kind of isolated bridge structure can not only meet the design requirements under various working conditions but can also effectively reduce the seismic effect on the bridge pier under the rare earthquake. However, near-fault ground motion with strong non-stationary characteristics adversely affects the seismic performance and design of the isolated bridge through support shedding, displacement of expansion joints, excessive relative displacement of pier beams, and falling beams caused by the collision of the main beams. What is more, the large bearing displacement and the isolation device failure can cause serious damage to the structure [9,10]. Therefore, evaluating the seismic performance of isolated bridges under near-fault ground motion is an important subject for study.

However, because of the uncertain structural and ground motion parameters, the probabilistic analysis method is generally used to study the seismic performance of bridges. 
The probabilistic approach offers an efficient way to deal with various uncertainties such as aleatory or epistemic uncertainties in structures and ground motions [11]. Recently, the performance-based seismic design theory of bridges has drawn attention to the probabilistic seismic capacity of structures at multi-performance levels, and the seismic fragility analysis method is the most effective method to evaluate the seismic performance of structures $[12,13]$. At present, the seismic fragility analysis of bridges mainly includes empirical analysis and numerical simulation analysis; empirical fragility analysis establishes fragility curves based on the damage to bridge structures in real disasters. However, owing to the lack of disaster damage data for bridge structures, application of this method is extremely limited [14]. The numerical fragility analysis method is based on the numerical simulation and dynamic response analysis of the bridge structure to establish the fragility curve. This method can effectively solve the problems resulting from the empirical method, so it is widely used in the study of the seismic fragility of bridges [15].

In fact, the bridge is a high-order statically indeterminate structure, and the failure of one member of the whole structure does not mean the failure of the whole structure. Compared with those of the individual components, the seismic performance of the whole bridge system deserves more attention [16]. However, under the influence of an earthquake, the main beams, supports, columns, and piers of the bridge system are mutually affected. Therefore, accurate simulation of the correlation between the seismic responses of various components is one of the difficulties in seismic fragility research when shifting from a single component to the whole bridge system $[17,18]$.

At present, in view of the correlation between the components in the overall bridge structure, it is assumed that the seismic responses of the components are either completely correlated or not, and the upper and lower boundary values of the fragility of the bridge system are obtained by numerical analysis. The upper bound value is conservatively used to describe the seismic fragility of structural systems $[19,20]$. However, when the bridge system contains a large number of components, the difference between the upper and lower limits of seismic fragility will be too wide [21,22]. The upper bound of the first-order limit method will obviously overestimate the seismic fragility of the structural system, which will seriously underestimate the safety and reliability evaluation of the entire bridge. In addition, the Monte Carlo sampling method can be used to establish the fragility curve of the bridge system, but the method needs to assume the edge and joint probability distribution types in advance when establishing the joint probability demand model $[23,24]$. However, there are still many problems in the above analysis methods, such as assuming a linear correlation between the seismic requirements of components, which involves a large amount of numerical sampling.

With the development of mathematical statistics, the copula theory, which deals with correlation between variables, has been gradually applied to the mechanical, civil, and hydraulic engineering fields [25]. At present, the copula function can describe not only the linear correlation between variables, but also the nonlinear correlation between variables, and is not limited by the edge distribution function [26]. The copula function model can accurately simulate the correlation characteristics between variables by separating the edge distribution of variables from the correlation between variables, thus simplifying the process of establishing the joint probability distribution model, which provides a new method for the seismic fragility assessment of the whole system of bridge structures.

Therefore, in this paper, we take an RC isolated continuous girder bridge as a case and use the performance-based probability analysis method to evaluate the seismic failure probability of the components and the bridge system. By considering the impact damage indexes of piers, bearings, and the collision of the main beams, based on the calculation of the seismic fragility of the piers, bearing components, and the collision of the main beams, a seismic fragility analysis of the isolation bridge system is carried out using the copula technique, and the results of this method and the first-order reliability theory method are compared to verify the accuracy and superiority of the copula method. In addition, in the seismic fragility analysis, to assess the uncertainty of the structural parameters, 100 near- 
fault ground motions are randomly selected from the PEER (Pacific Earthquake Engineering Research) database, and a large number of random ground motion structural samples are established. Thereafter, based on the damage indexes of bridges under different failure states, the seismic fragility curves of each component and of the isolated bridge system are obtained according to the capacity and demand of the structure. Finally, according to the actual seismic demand of similar as-built isolated bridges, the probabilities of damage states are obtained, and a basis is presented as a guide to isolated structural seismic design, reinforcement, and maintenance decision making, etc.

\section{Calculation Methods}

\subsection{The Seismic Fragility Analysis Method}

Structural seismic fragility is the probability that the structural damage will exceed a specified value when the ground motion intensity reaches a certain value [27-29]. The seismic fragility of bridges can be expressed as:

$$
F_{R}(a)=P[E D P \geq L S \mid I M=a]=\int_{V}^{\infty} f_{R \mid I M}[r \mid a] d r
$$

where, $F_{R}(a)$ is seismic fragility, $P$ is the probability of the structure failure exceeding a specified value, EDP is the engineering demand parameter, $L S$ is the state limit of structure, $I M$ is the intensity coefficient of ground motion; $f_{R \mid I M}[r \mid a]$ means that, when the ground motion intensity is $I M$, the structure (component) of a certain engineering demand parameter $(E D P)$ has reached or exceeded the conditional probability density of a specified damage state.

Assuming that the relationship between EDP and IM follows the log normal distribution, the mean value of the structure (or component) is:

$$
\stackrel{\Lambda}{\mathrm{D} P}=b(I M)^{c}
$$

where, $c$ and $b$ are correlation coefficients.

The seismic fragility of the structural limit state can be calculated. The smooth "seismic fragility curve" is obtained by statistical curve fitting:

$$
P=[E D P \geq L S \mid I M]=1-\Phi\left(\frac{\ln \left(L S_{m}-\ln \left(b I M^{C}\right)\right.}{\sqrt{\beta_{L S}^{2}+\beta_{E D P}^{2}}}\right)
$$

where, $\Phi$ is the cumulative density function of standard normal distribution, $L S_{m}$ is $\log$ normal distribution under structural damage states, $\beta_{L S}$ is log standard deviation of structural capacity, $\beta_{E P D}$ is log standard deviation of structural requirements.

\subsection{Seismic Fragility Analysis of Bridge Systems Based on the Copula Technique}

The bridge structure is a series system composed of all the structural members of the bridge. Therefore, to evaluate the failure probability of the overall structure of the bridge, it is necessary to consider the seismic fragility evaluation of each of its components. The reliability theory is used to estimate the failure probability of the structure under each damage state:

$$
P_{f_{s}}=P\left[g_{1}(X) \leq 0, g_{2}(X) \leq 0, \ldots g_{i}(X) \leq 0\right]
$$

where, $P_{f s}$ is the failure probability of the bridge structural system, $g_{1}(X), g_{2}(X), g_{i}(X)$ and $g_{i}(X)$ are the functions of failure probability for each component of the bridge system. The probability of the simultaneous failure of all components is:

$$
\begin{aligned}
& P\left[g_{1}(X) \leq 0, g_{2}(X) \leq 0, \ldots g_{i}(X) \leq 0\right] \\
& =P\left\{F_{1}\left[g_{1}(X)\right] \leq F_{1}(0), F_{2}\left[g_{2}(X)\right] \leq F_{2}(0), \ldots, F_{i}\left[g_{i}(X)\right] \leq F_{i}(0)\right\} \\
& =C\left[F_{1}(0), F_{2}(0), \ldots, F_{3}(0)\right]=C\left(P_{f 1}, P_{f 2}, \ldots, P_{f i}\right)
\end{aligned}
$$


Then, the failure probability of the bridge system considering the correlation of components is obtained:

$$
\begin{aligned}
P_{f_{s}} & =P\left[g_{1}(X) \leq 0 \cup g_{2}(X) \leq 0 \ldots \cup g_{i}(X) \leq 0\right] \\
& =P_{f 1}+P_{f 2}+\ldots+P_{f i}-C\left(P_{f 1}, P_{f 2} \ldots P_{f i}\right)
\end{aligned}
$$

where, $P_{f 1}, P_{f 2}, P_{f i}$ are the failure probabilities of each component of the bridge system; $C$ is the copula function.

The seismic fragility of the bridge system can be obtained by substituting the seismic fragility of the bridge components into Equation (3). According to Equation (6), the copula function is the key to solving the fragility of the bridge system.

The above method can easily determine the seismic fragility of each component using IDA calculation results. However, it is difficult to calculate the seismic fragility of two or more components because of the interaction between components. This is because the joint probability distribution of multiple components cannot be directly established by the marginal distribution function of a single component. Therefore, this paper will use the copula technique to analyze the random seismic fragility of the bridge system.

The copula technique provides a common method for describing the nonlinear correlation between random variables. The copula function is defined as an n-dimensional probability distribution on $[0,1]^{n}$, which is expressed as [30]:

$$
C\left(u_{1}, u_{2}, \ldots u_{n}\right)=P\left(U_{1} \leq u_{1}, U_{2} \leq u_{2}, \ldots U_{n} \leq u_{n}\right)
$$

where, $u_{1}, u_{2}, \ldots u_{n}$ is the sample set of uniform random variable $U$.

Given that $F_{i}\left(x_{i}\right)$ is an edge probability distribution, its joint probability distribution is represented by $F\left(x_{1}, x_{2}, \ldots x_{n}\right)$. Then, the relationship between $F_{i}\left(x_{i}\right)$ and $F\left(x_{1}, x_{2}, \ldots x_{n}\right)$ can be established by the copula function.

$$
F\left(x_{1}, x_{2}, \ldots x_{n}\right)=C\left(F_{1}\left(x_{1}\right), F_{2}\left(x_{2}\right), \ldots F_{n}\left(x_{n}\right)\right)=C\left(u_{1}, u_{2}, \ldots u_{n}\right)
$$

If $F_{i}\left(x_{i}\right)(i=1, \ldots, n)$ are all continuous functions, then the copula function $C\left(u_{1}, u_{2}, \ldots u_{n}\right)$ is unique. It can be seen that the copula function connects the joint distribution of variables with their edge distribution. As a result of the copula function, the joint distribution function can be expressed explicitly with the edge distribution function. Although it is the connection function of the edge distribution, the form of the copula function is not limited by the edge distribution function.

$$
P\left(X_{1}, X_{2}, \ldots X_{n} \mid I M\right)=C\left(P\left(x_{1}\right), P\left(x_{2}\right), \ldots P\left(x_{n}\right) \mid I M\right)
$$

where, $P\left(X_{i}\right)(i=1, \ldots, n)$ represents the seismic fragility of a single component, which can be obtained from Equation (3), and $n$ represents the number of components damaged at the same time. By substituting Equation (9) into Equation (6), the seismic fragility of the bridge system can be expressed as:

$$
\begin{aligned}
& P_{f_{s}}=\sum_{i=1}^{m} P\left(X_{i} \mid I M\right)-\sum_{1 \leq i \prec j \leq m} C\left(P\left(X_{i}\right), P\left(X_{j}\right) \mid I M\right)+ \\
& \sum_{1 \leq i \prec j \prec k \leq m} C\left(P\left(X_{i}\right), P\left(X_{j}\right), P\left(X_{k}\right) \mid I M\right)+\ldots+ \\
& (-1)^{m-1} C\left(P\left(X_{1}\right), P\left(X_{2}\right), \ldots, P\left(X_{m}\right) \mid I M\right)
\end{aligned}
$$

The seismic fragility of the bridge system can be accurately calculated by Equation (10). The key task of building the seismic fragility curve of the bridge system with the copula method is determining the edge distribution of each component of the bridge system and the best fitting copula function that accurately reflects the correlation of the seismic demand of each component [31]. 
In short, the key to the seismic fragility analysis of a bridge system is establishing the joint probability distribution function of the pier, support, and other components. However, it is difficult to directly establish the joint probability distribution function between components because of the correlation between the seismic requirements of the components. Therefore, the advantage of using the copula function method is that the correlation between the seismic requirements of components and the probability distribution function of each component edge can be separated, thus simplifying the modeling process of the joint distribution function. In addition, the copula function method not only considers the nonlinear correlation between the seismic requirements of components but also minimizes the numerical sampling, which greatly improves the computational efficiency.

\subsection{Selection of the Best Fitting Copula Function}

The empirical distribution function can be used to estimate the marginal distribution of the seismic requirements of a component since it is more flexible and has fewer limitations. Because the normal function and $t$ copula function can describe the symmetry between component seismic requirements, an empirical distribution-based analysis method was used in this study to select the most suitable copula from the commonly used copula functions (normal function and $t$ copula function). The normal copula function and $t$ copula function with correlation coefficient $\rho$ are expressed as:

$$
\begin{gathered}
C\left(X_{1}, X_{2} \cdots, X_{n} ; \rho\right)=\Phi_{\rho}\left(\Phi^{-1}\left(u_{1}\right), \Phi^{-1}\left(u_{2}\right) \cdots, \Phi^{-1}\left(u_{n}\right)\right) \\
C\left(X_{1}, X_{2} \cdots, X_{n} ; \rho, v\right)=\Phi_{\rho, v}\left(T_{v}^{-1}\left(u_{1}\right), T_{v}^{-1}\left(u_{2}\right) \cdots, T_{v}^{-1}\left(u_{n}\right)\right)
\end{gathered}
$$

where, $\Phi_{\rho}$ is an n-dimensional standard normal distribution with $\rho, \Phi^{-1}$ is the inverse normal distribution, $\Phi_{\rho, v}$ is the $n$-dimensional $t$ distribution with $\rho$ and $v$, and $T^{-1}$ is the inverse $t$ distribution.

Furthermore, the marginal distribution function based on the seismic demand of the component, and the empirical joint distribution function expressed by the empirical copula function are defined as:

$$
\hat{C}\left(u_{1}, u_{2}, \ldots, u_{n}\right)=\frac{1}{n} \sum_{i=1}^{n} I_{\left[F_{n}\left(x_{1 i}\right) \leq u_{1}\right]} \bullet I_{\left[F_{n}\left(x_{2 i}\right) \leq u_{2}\right]} \ldots \bullet I_{\left[F_{n}\left(x_{m i}\right) \leq u_{m}\right]}
$$

where $F_{n}\left(x_{j i}\right)(i=1, \ldots, n ; j=1, \ldots, m)$ denotes the marginal probability distribution function of components. $I(\bullet)$ denotes the indicator function, which is equal to 1 if the value of component marginal distribution is smaller than $u_{i}$, otherwise, it is equal to 0 .

For the above two copula functions as alternative functions, the copula function with the smallest distance is the best fitting copula function describing the correlation between component seismic requirements. The squared Euclidean distance between the alternative function and the empirical copula function is defined as:

$$
d^{2}=\sum_{i=1}^{n}\left|\hat{C}\left(u_{1 i}, u_{2 i}, \cdots, u_{m i}\right)-C\left(u_{1 i}, u_{2 i}, \cdots, u_{m i}\right)\right|^{2}
$$

where $C(\bullet)$ is the alternative copula function, $\hat{C}$ is the empirical copula function.

In short, according to the component seismic requirements obtained using IDA, the correlation parameters of two commonly used copula functions were estimated, and the squared Euclidean distance was calculated with Equation (14). Then the minimum distance criterion was used to select the best fitting copula function. Finally, the system fragility was obtained by substituting the fragility of each component and the best fitting copula function into Equation (10). 


\subsection{Basic Steps of Seismic Fragility Analysis}

In this paper, the Latin hypercube sampling method (LHS) was applied to incorporate the uncertainty of the structure, and the randomness of ground motion was selected from the PEER (Pacific Earthquake Engineering Research) database for the seismic fragility analysis. The whole research process is summarized, and the technical route is given as follows (Figure 1).

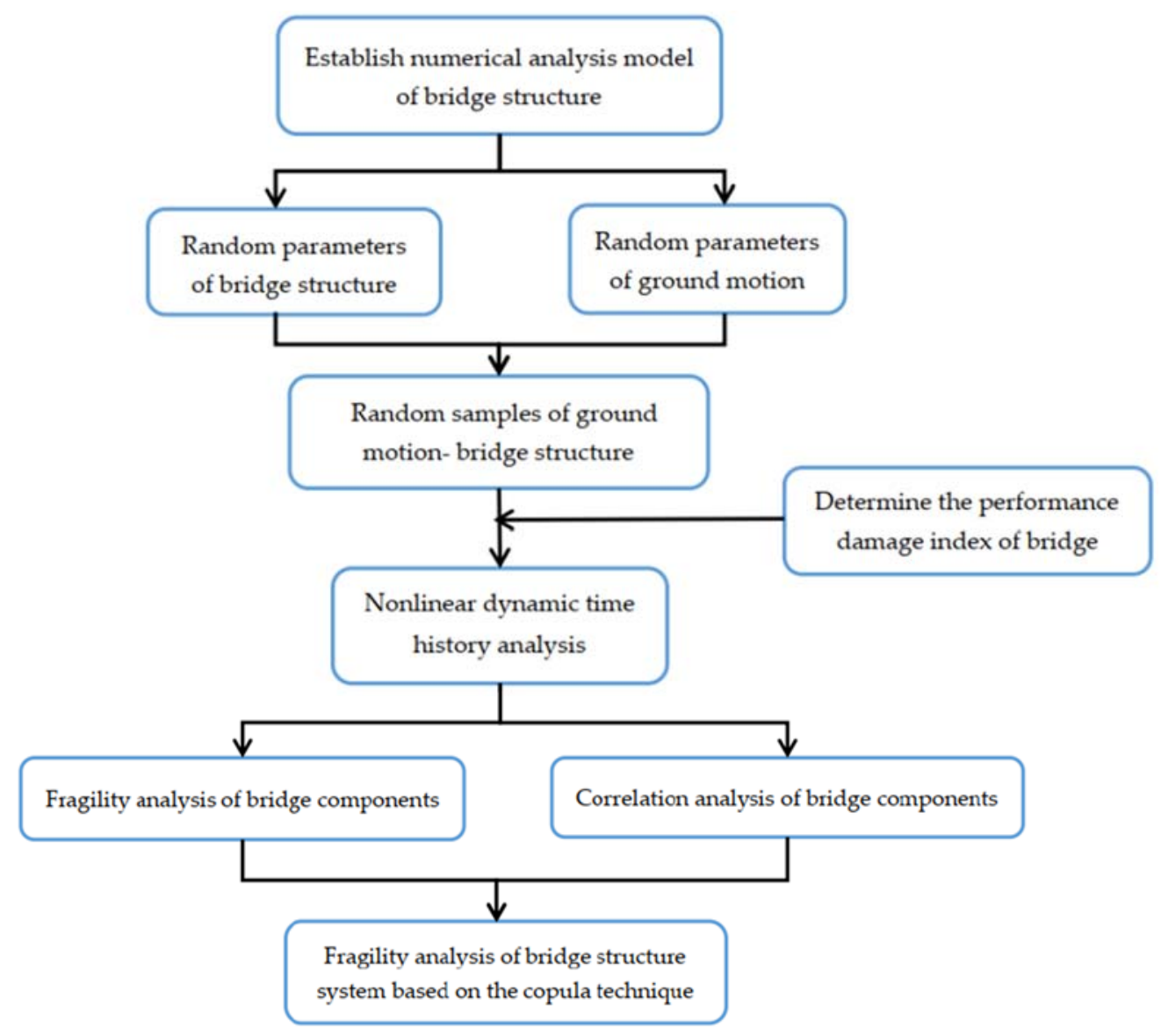

Figure 1. The technical route of the research process.

\section{Application}

3.1. The Isolated Bridge Geometry and Finite Element Model

The study object of this article is a six-span reinforced concrete continuous girder bridge with a total length of $120 \mathrm{~m}$. The bridge arrangement is shown in Figure 2. The bridge superstructure is a $6 \times 20 \mathrm{~m}$ cast-in-place C40 concrete box girder with a beam height of $1.3 \mathrm{~m}$. The lower part of the structure is an RC circular pier column of C30 concrete. No. 1 and No. 5 piers are double-column piers $1.3 \mathrm{~m}$ in diameter and $8 \mathrm{~m}$ in height; No. 2, 3, and 4 piers are variable cross-section one-column circular bridge piers with a height of $8 \mathrm{~m}$ and diameter of $1.5 \mathrm{~m}$. The main girder and the pier top are connected to an LRB500 isolation bearing by setting expansion joints on both sides of the stage. The bridge pier foundation material is $\mathrm{C} 30$ concrete. The seismic fortification intensity is 8 degrees in the area, and the site class is II. 


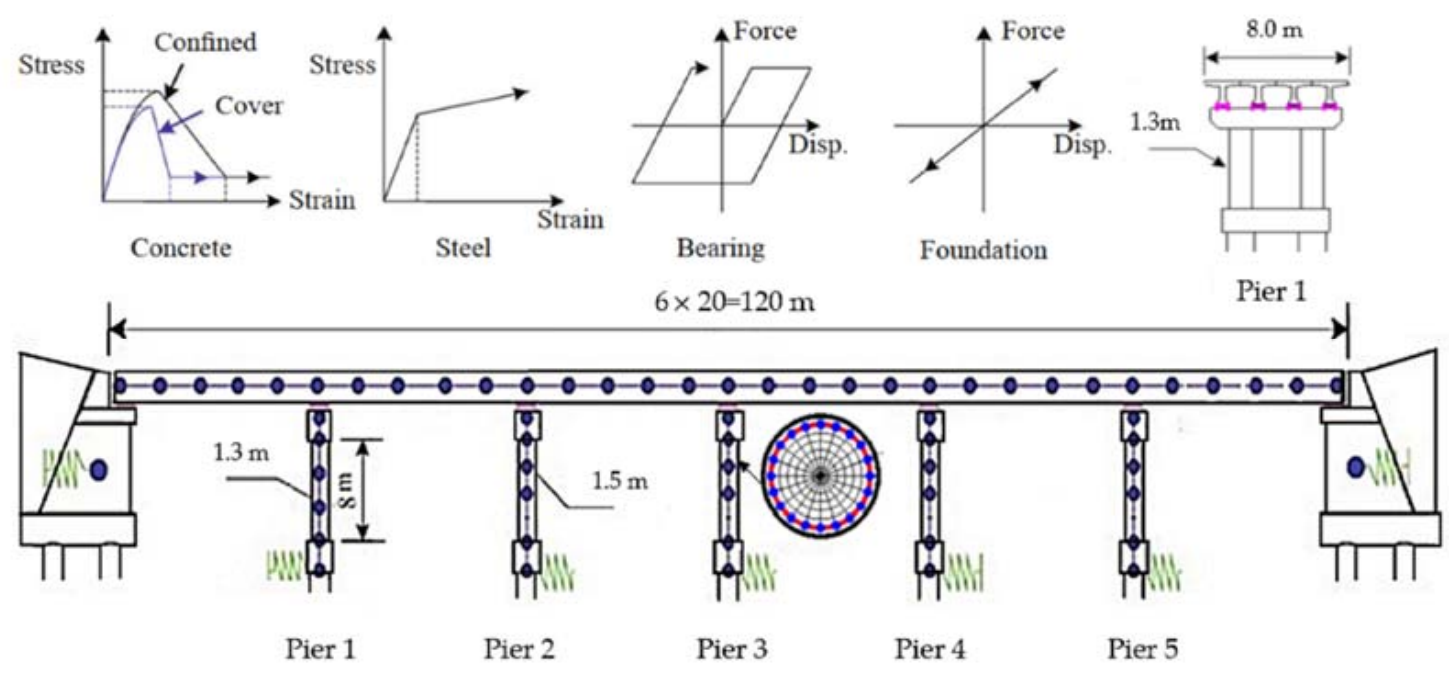

Figure 2. The isolated girder bridge structural configuration.

The finite element dynamic analysis model of the isolated bridge structure was established using OpenSees software [32], and the seismic response of the structure was measured by only the longitudinal seismic motion. The superstructure was modeled with elastic beam-column elements because they remain undamaged and in an elastic state in earthquakes. The damping was simulated with Rayleigh damping [23]. The bearings were modeled using zero-length elements [33], and the shear force-deformation relationship was assumed to be perfect elastic-plastic [34]. Regarding the pier, it often enters the plastic stage, and the plastic hinge appears. Therefore, in the time history analysis, the piers were simulated by nonlinear beam-column elements. The cross section of the element was defined by fibers with the corresponding material stress-strain relationship. The concrete behavior was modeled with Concrete01 in OpenSees. This material was defined with the Kent-Scott-Park model [35]. The reinforcing steel was modeled with Steel 01 in OpenSees, and the constitutive model is shown in Figure 1. The expansion joint between the main beam and the abutment was modeled with a nonlinear contact Gap unit, as shown in Figure 3. It is worth noting that when solving the contact collision problem, it is required that the two components in the collision should not have initial penetration, otherwise the wrong calculation results will be obtained. Therefore, when establishing the model, the spatial clearance at the contact should be maintained as far as possible, so as to conform to the actual spatial position of the bridge [36]. Therefore, this paper assumed that the value of the relative displacement of the abutment and the girder was set, and the collision would occur when the open value was reached.

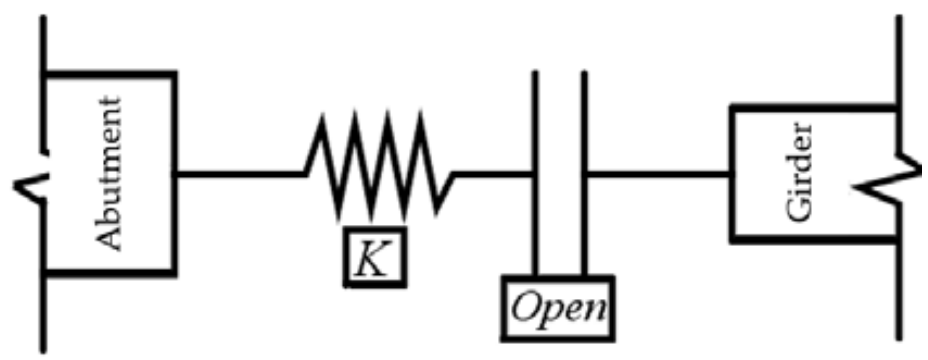

Figure 3. The element model for gap.

\subsection{Selection of Near-Fault Ground Motion Records}

The object of this paper was choosing near-fault ground motion. The accuracy and efficiency of the structural fragility analysis relies on selecting a reasonable classification and the appropriate number of seismic ground motions. The seismic ground motions should meet two requirements: the first is the ability to simulate the random process 
of an earthquake disaster itself, and the second is the selection of a large number of adequate seismic ground motions to reduce the impact of ground motion uncertainty on the results of the seismic fragility analysis. The general criterion for ground motion selection was to propagate uncertainty in the magnitude and epicentral distance. In the present study, a suite of ground motions typical of the bridge location were chosen from the Next Generation Attenuation database of the Pacific Earthquake Engineering Research Center (NGA-West2). Then, 100 near-field ground motions with a fault distance of less than $20 \mathrm{~km}$ and with significant velocity pulse effect were selected. The general properties of the selected ground motions were as follows: (1) the source-to-site distance $(r)$ was $0 \leq r \leq 20 \mathrm{~km}$, (2) the moment magnitude of the selected near-field ground motions ranged from 6.5 to 7.6 , (3) the average shear-wave velocity of the upper $30 \mathrm{~m}$ was accepted from 260 to $500 \mathrm{~m} / \mathrm{s}$, and (4) there was significant pulse velocity (a pulse-like waveform with a long period, rich medium and long-period components, and a large peak value). The selected near-fault ground motions covered a wide range of intensities to ensure that the selected suite represented both large and small earthquakes [23]. The distribution of PGAs in 100 near-fault ground motion records is shown in Figure 4.

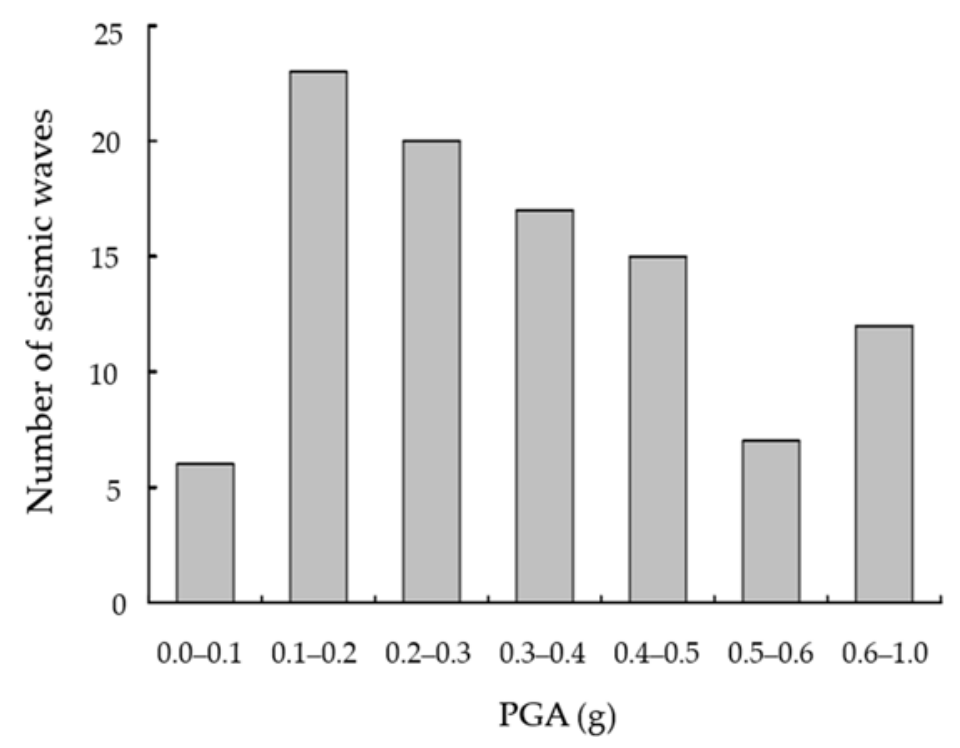

Figure 4. PGA distribution near-fault ground motion record.

\subsection{Stochastic Simulation of Near-Fault Ground Motion-Isolated Bridge Samples}

For isolated bridges, uncertainty parameters include yield strength of steel (Fy), quality of the upper structure ( $\rho$ is bulk density), the compressive strength of concrete (Fc), preyield stiffness of bearing (K1), and yield shear of bearing (Qy) [37,38]. The main uncertainty parameters and their probability distributions were processed with the Latin hypercube sampling (LHS) approach in the present study. In this paper, the curvature ductility of the pier bottom and the displacement of the isolation bearing were selected as the evaluation indexes, and the parameters of each group of structural samples were changed [39,40]. In order to eliminate the difference between each uncertain parameter in the structural analysis, the data above were normalized, and the sensitivity results of each structural parameter under the action of PGA (1.0 g) ground motion were obtained. The structure parameters of the sensitive variable probability distribution statistics are shown in Table 1. The analysis showed that the yield strength of steel, the quality of the upper structure, the compressive strength of concrete, the pre-yield stiffness of bearing (K1), and the yield shear of bearing (Qy) were sensitive to the seismic response of bridge structures. Thereafter, LHS (Latin hypercube sampling) was used to randomly combine five main parameters to form 10 isolated bridge structure samples, which ensured that these parameters (five main parameters) were taken equally from their probability distributions. Finally, combining the 10 isolated bridge structural samples with the selected 100 near-fault ground motion 
records, a group of 10 near-fault ground motion-isolated bridge samples were developed to determine the isolated bridge service life (seismic performance analysis).

Table 1. Statistics of the random variables.

\begin{tabular}{ccccc}
\hline Random Variable & $\begin{array}{c}\text { Probability } \\
\text { Distribution }\end{array}$ & Average Value & $\begin{array}{c}\text { Standard } \\
\text { Deviation }\end{array}$ & Unit \\
\hline Fy & normal & 385.42 & 28.32 & $\mathrm{Mpa}$ \\
FC & normal & 27.68 & 5.23 & $\mathrm{Mpa}$ \\
$\rho$ & normal & 28,930 & 2530 & $\mathrm{~N} / \mathrm{m}^{3}$ \\
K1 & uniform & 12,357 & - & $\mathrm{kN} / \mathrm{m}$ \\
Qy & uniform & 54.83 & - & $\mathrm{kN}$ \\
\hline
\end{tabular}

\subsection{Definition of Seismic Damage to Isolated Girder Bridges}

The seismic performance level of structures is a finite state of damage, and the damage to structures should be related to the level of performance (FEMA 2008). Bridge structure damage from earthquake is mainly damage to the bridge pier, bearing, and main beam component, and especially to the bridge pier, which is the most fragile component. In this paper, the damage state of the bridge was defined in three aspects: the failure of the bridge piers, the failure of the isolated bearing, and the collision of the main beam (girder). Thus, the corresponding damage index was determined.

\subsubsection{Bridge Pier}

With the curvature of piers as engineering demand parameters (EDPs), and with the curvature ductility ratio $\mu$ as damage index, the damage index of bridge piers is determined by the moment-curvature relationship of the sections of different damage conditions [41,42]. Earthquake damages indicated that the bottom of the bridge pier was the first failure. Therefore, the damage state was defined by the curvature of the bottom section of the bridge pier, and the damage state and damage index were described at all levels [43], as shown in Table 2.

Table 2. Damage status and description of damage index for piers.

\begin{tabular}{cccccc}
\hline Damage State & Intact & Minor Damage & Medium Damage & Serious Damage & Collapse \\
\hline Failure criterion & $\phi \leq \phi^{\prime}{ }_{y}$ & $\phi_{y}^{\prime} \leq \phi \leq \phi_{y}$ & $\phi_{y} \leq \phi \leq \phi_{d}$ & $\phi_{d} \leq \phi \leq \phi_{u}$ & $\phi \geq \phi_{u}$ \\
\hline
\end{tabular}

Note: $\phi_{y}^{\prime}$ is the first reinforcement yielding, concrete cracking; $\phi_{y}$ is the appearance of the plastic hinge of the section; $\phi_{d}$ is the maximum value of the bending capacity; $\phi_{u}$ is the limit bending state.

\subsubsection{Isolation Bearing}

The failure state of the isolated bearing is mainly determined by the displacement and shear strain of the bearing. Five damage states, including basically intact, minor damage, moderate damage, severe damage, and collapse, were defined by Choi according to the displacement of the bearings [44]. Here, displacement of the isolated bearing based on bearing shear strain was adopted as the basis for evaluating earthquake damage. The definition of the deformation rate of the bearing under different damage states is given in Table 3.

Table 3. Description of isolated bearing damage indexes (unit: $\mathrm{mm}$ ).

\begin{tabular}{cccccc}
\hline State & Intact & $\begin{array}{c}\text { Minor } \\
\text { Damage }\end{array}$ & $\begin{array}{c}\text { Moderate } \\
\text { Damage }\end{array}$ & $\begin{array}{c}\text { Severe } \\
\text { Damage }\end{array}$ & Collapse \\
\hline Index & $d_{\Delta} \leq 100 \% \gamma$ & $d_{\Delta} \leq 150 \% \gamma$ & $d_{\Delta} \leq 200 \% \gamma$ & $d_{\Delta} \leq 250 \% \gamma$ & $d_{\Delta}>250 \% \gamma$ \\
\hline
\end{tabular}

Note: $d_{\Delta}$ is relative horizontal displacement, $\gamma$ is the total thickness of the rubber layer. 


\subsubsection{The Girder End and the Abutment Collision}

Under the action of near-fault ground motion, a large relative displacement may occur at the girder end. When the relative displacement of the motion reaches or exceeds the width of the expansion joint between the girder end and the abutment, a collision may occur between the girder end and the abutment. Furthermore, this paper assumed that the expansion between the girder ends and the abutment joint width was $100 \mathrm{~mm}$ (gap $=100 \mathrm{~mm}$ ). In the analysis, the change in temperature and the effect of material variation on the width of the expansion joint were considered. Under the action of a strong earthquake, when the relative displacement of the girder end reached or exceeded $100 \pm 10 \mathrm{~mm}$, the girder end was considered to collide with the abutment.

\subsection{Probabilistic Seismic Demand Model and Correlation Analysis for Bridge Structure}

The probabilistic seismic demand model describes the relationship between structural seismic demand parameters and the ground motion intensity index. Based on the time history analysis of 10 random samples of isolated bridge ground motion, the relationship between the maximum response of dimensionless components and the ratio of required capacity $\mu$ under each ultimate failure state and the seismic intensity PGA was obtained. Furthermore, the fitting result obtained by logarithmic regression analysis (that is, the least squares method used for regression analysis of seismic demand and ground motion parameters of structural components) was the probabilistic seismic demand model of the structure. The relationship between the demand capacity ratio $\mu$ of each component of the bridge structure under different failure states and the peak seismic acceleration PGA can be expressed as follows:

$$
\ln (\mu)=A \ln (P G A)+B
$$

where, $\mu$ is the requirement capacity ratio of the structure; $A$ and $B$ are regression coefficients.

According to Equation (15), the regression analysis of each component of the bridge system under various failure states could be carried out, and the correlation analysis of the seismic demands of each component could be carried out according to the analysis results of nonlinear dynamic time history, and the relevant parameters of the seismic demands of the structural components of the bridge were obtained, as shown in Table 4 .

Table 4. Correlation coefficients of structure seismic demands.

\begin{tabular}{cccc}
\hline The Correlation Coefficient & $\ln \mu(\varphi)$ & $\ln \mu\left(d_{\Delta}\right)$ & $\ln \mu($ Gap $)$ \\
\hline $\ln \mu(\varphi)$ & 1 & 0.892 & 0.753 \\
$\ln \mu\left(d_{\Delta}\right)$ & 0.892 & 1 & 0.892 \\
$\ln \mu(\mathrm{Gap})$ & 0.753 & 0.813 & 1 \\
\hline
\end{tabular}

It can be seen from Table 4 that the correlation between pier and abutment collision was relatively weak, but the minimum correlation coefficient was still greater than 0.75 . The results showed that the seismic requirements of each component of the bridge structure were significantly correlated.

\section{Results and Discussion}

\subsection{The Seismic Fragility Analysis of Isolated Bridge Components}

As an example, owing to limited space, only the No. 3 pier is provided, based on the damage index. The pier and isolation bearing of the seismic fragility curves under different damage conditions are plotted (obtained from Equation (3)) in Figures 5 and 6, respectively. 


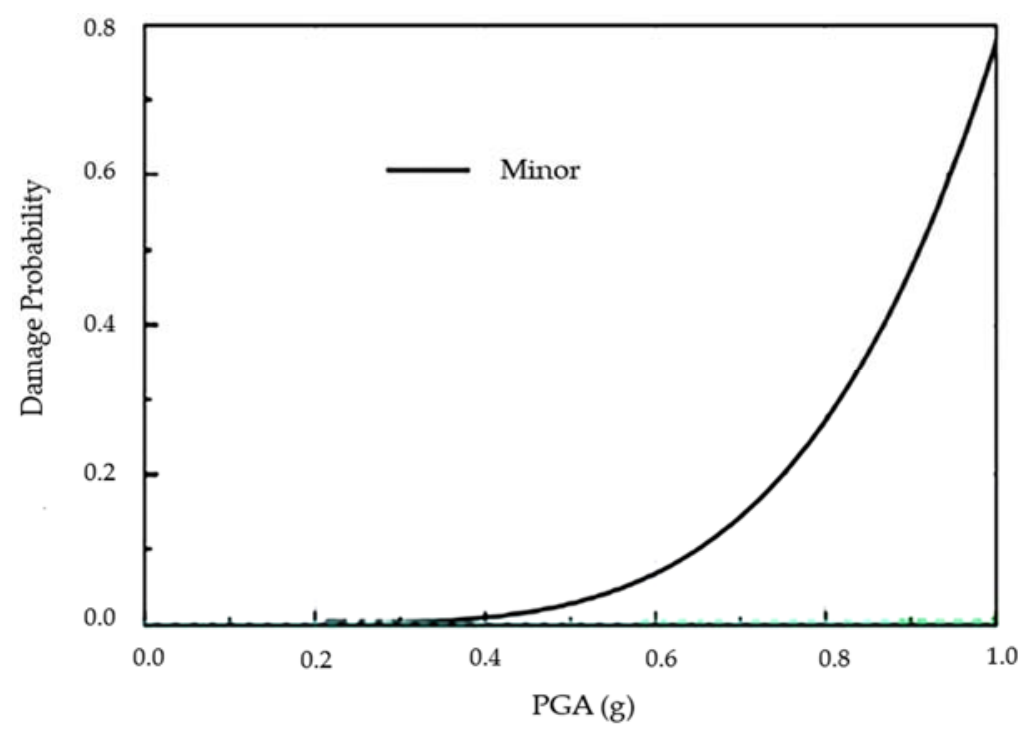

Figure 5. The seismic fragility curves of the pier.

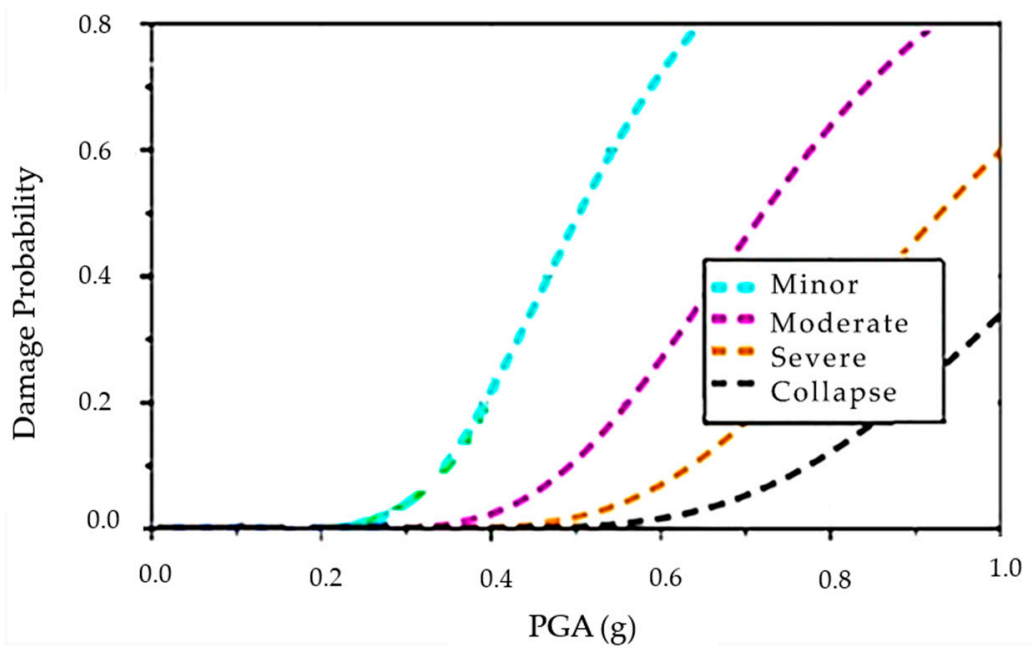

Figure 6. The seismic fragility curves of the isolated bearing.

In order to analyze the structure under the earthquake action, it was assumed that when the ground motion intensity was $0.11 \mathrm{~g}(\mathrm{PGA}=0.11 \mathrm{~g})$, it was a frequent earthquake, and when the ground motion intensity was $0.51 \mathrm{~g}(\mathrm{PGA}=0.51 \mathrm{~g})$, it was a rare earthquake.

As is shown in Figure 5, the No. 3 pier with isolated bridges remained intact under frequent earthquake action $(\mathrm{PGA}=0.11 \mathrm{~g})$. In the case of rare earthquake action $(\mathrm{PGA}=0.51 \mathrm{~g})$, the probability of minor damage to the bridge pier was $4 \%$, but without moderate damage, severe damage, complete destruction, or other incidents. Minor damage did not occur in the frequent earthquake, and it had only a small probability of occurring from the rare earthquake. This was because the pier could bear a greater force, which reflected the requirements of ductility design of bridge components. It showed that the seismic demand on the bridge pier was greatly reduced in the isolation bearing structure.

According to the data shown in Figure 6, under frequent earthquake action (PGA $=0.11 \mathrm{~g}$ ), the isolated bearing was not easily damaged. However, under rare earthquake action $(\mathrm{PGA}=0.51 \mathrm{~g})$, damage to the bearing occurred; the probability of minor, moderate, and severe damage was 52,11 , and $4 \%$, respectively, but a collapse of the isolated bearing did not happen. Compared with the bridge pier, the seismic fragility of the isolated bearing played a key role in the safety control of the isolated continuous girder bridge. This was mainly because the isolated continuous girder bridge canceled the braking pier, the 
deformation of the isolated bearing was relatively large, so the seismic fragility of the isolated bearing was large.

In order to compare the failure probability of collision between the girder end and the abutment of the general bridge (without isolation device) and of the isolated bridge, the seismic fragility curves of the collisions between the girder and the abutment of two different bridges are given in Figure 7. Under the frequent earthquake action (PGA $=0.11 \mathrm{~g}$ ), there was no collision between the girder end and abutment of these two types of bridges. However, in the case of rare earthquake action (PGA $=0.51 \mathrm{~g}$ ), the probability of collision between the girder end and the abutment of the general bridge was about $78 \%$, and the probability of collision between the girder end and the abutment of the isolated bridge was $63 \%$. Therefore, for the bridge constructed using the isolation technology, the probability of collision was $15 \%$ lower than that of the general bridge. The main reason was that the relative displacement of the beam members from the earthquake was greatly reduced because of the isolation bearings.

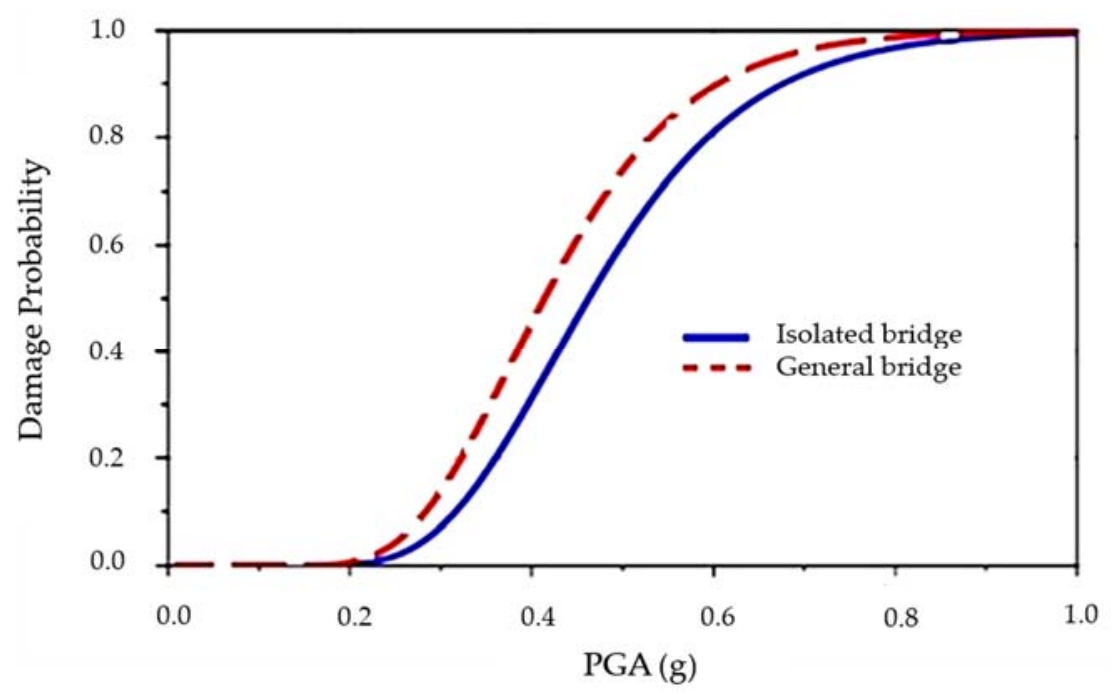

Figure 7. The seismic fragility curves of the girder collision (general bridge and isolated bridge).

\subsection{Comparative Analysis of the Seismic Fragility of the Bridge Structure System Based on First-Order Reliability Theory and Copula Technique}

In order to verify the accuracy of the copula function method, the upper and lower limits of the seismic fragility of bridge structures based on the first-order reliability theory were considered. According to the reliability theory, when the seismic demand on components is completely related, the maximum seismic fragility of components is the system seismic fragility, which constitutes the lower bound of the first-order limit method; when the seismic demand on components is completely unrelated, any component failure will lead to the failure of the series system, which constitutes the upper bound of the system seismic fragility. Therefore, the first-order boundary of the seismic fragility of the bridge system is:

$$
\max _{i=1}^{m}\left[P\left(F_{i}\right)\right] \leq P_{\text {sys }} \leq 1-\prod_{i=1}^{m}\left[1-P\left(F_{i}\right)\right]
$$

where, $P\left(F_{i}\right)$ indicates the probability of failure in the $i$-th damage state. $P_{s v s}$ is the failure probability of the bridge system in each damage state. $m$ is the number of bridge system components.

By substituting the seismic fragility function of piers and bearings into Equation (16), the upper and lower boundaries of the seismic fragility of the system could be obtained. For comparison, the seismic fragility boundary of the bridge system based on the copula function and that based on the boundary method of first-order reliability theory are shown in Figure 8. 


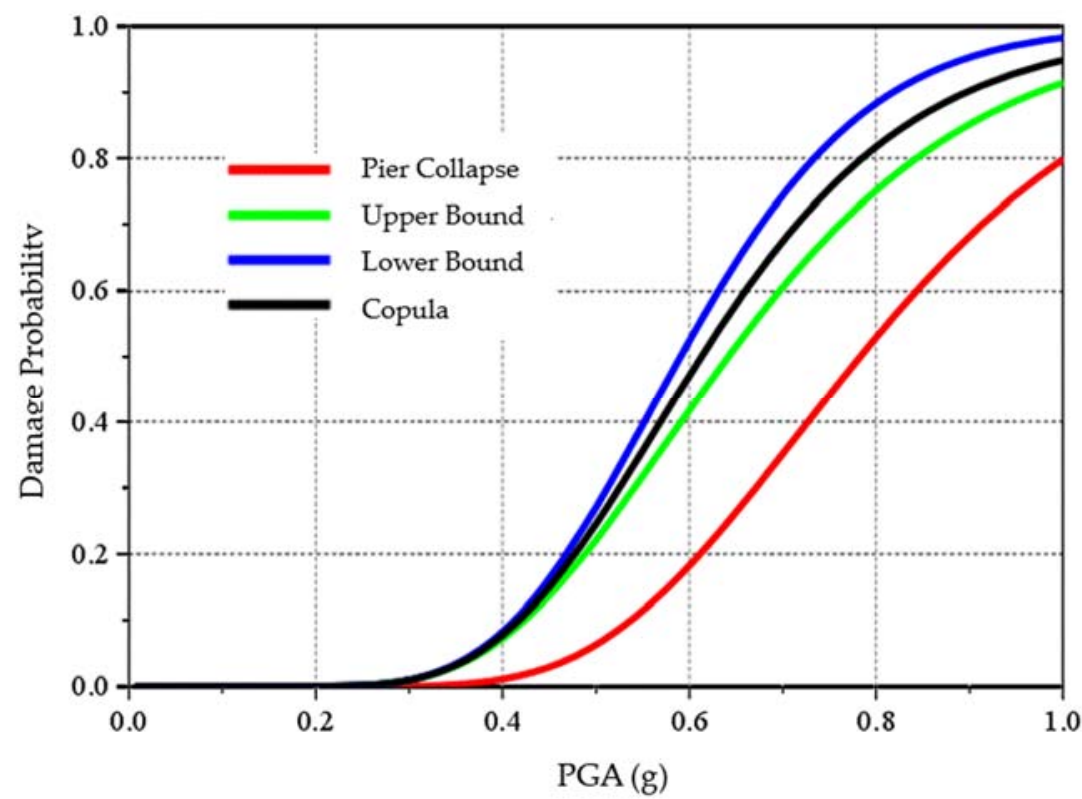

Figure 8. The seismic fragility curve of the overall bridge based on the copula function method.

As seen in Figure 8, the seismic fragility curve of the overall structure based on the first-order reliability theory could be used to evaluate the failure probability range of the overall structure of the bridge under earthquake action. Under the rare earthquake action $(\mathrm{PGA}=0.51 \mathrm{~g})$, the failure probability of the overall structure of the bridge was between 21 and $28 \%$, and the upper boundary seismic fragility curve of the failure probability of the overall structure of the bridge and the seismic fragility curve of the bearing failure almost coincided. However, the seismic fragility curve of the bridge system based on the copula function was between the upper and lower bounds of the first-order boundary in the whole range of seismic intensity, and it was closer to the lower bound. If the lower bound described the seismic fragility of the bridge system, it would underestimate the fragility of the structure, while if the upper bound described the seismic fragility of the bridge system, it would obviously overestimate the fragility of the structure. With the increase in ground motion intensity, the difference between the upper and lower bounds obtained by the first-order reliability theory limit method increased, and the difference between the upper and lower bounds obtained by the copula function method and the seismic fragility of bridge system also increased. Therefore, when the intensity of ground motion is large, the limit method of the first-order reliability theory will fail to estimate the fragility of the seismic system of the structure and cannot reasonably evaluate the safety and reliability of the structure.

It can also be seen from Figure 8 that the seismic fragility curve of the bridge system based on the copula function method, under the rare earthquake action (PGA $=0.51 \mathrm{~g}$ ), indicated that the failure probability of the whole bridge structure was $19 \%$. However, no matter whether they were based on the first-order reliability theory or the copula function method for seismic fragility analysis, the pier and the bearing of the bridge structure system will not fail under frequent earthquake action $(\mathrm{PGA}=0.11 \mathrm{~g})$, and it is more likely to cause minor or medium damage. In the rare earthquake action $(\mathrm{PGA}=0.51 \mathrm{~g})$, the probability factors of complete failure of the pier and of the bearing were 8 and $21 \%$, respectively. This embodied the structural requirements for multiple seismic designs.

In conclusion, compared to the first-order reliability theory, the failure probability of the whole bridge structure based on copula function analysis was smaller and the probability interval was safer and more reliable. 


\subsection{Comparative Analysis of Seismic Vulnerability between the Isolated Bridge System and} General Bridge System

The comprehensive analysis from the previous section showed that there are significant dependences among component seismic demands since the components interact with each other under earthquake excitation. Therefore, the copula technique was applied to evaluate the seismic damage probability for the bridge structure system.

In order to compare the effect of the seismic isolation system, the seismic fragility curves of the general bridge and the isolated bridge were devised based on the copula function method, as shown in Figure 9.

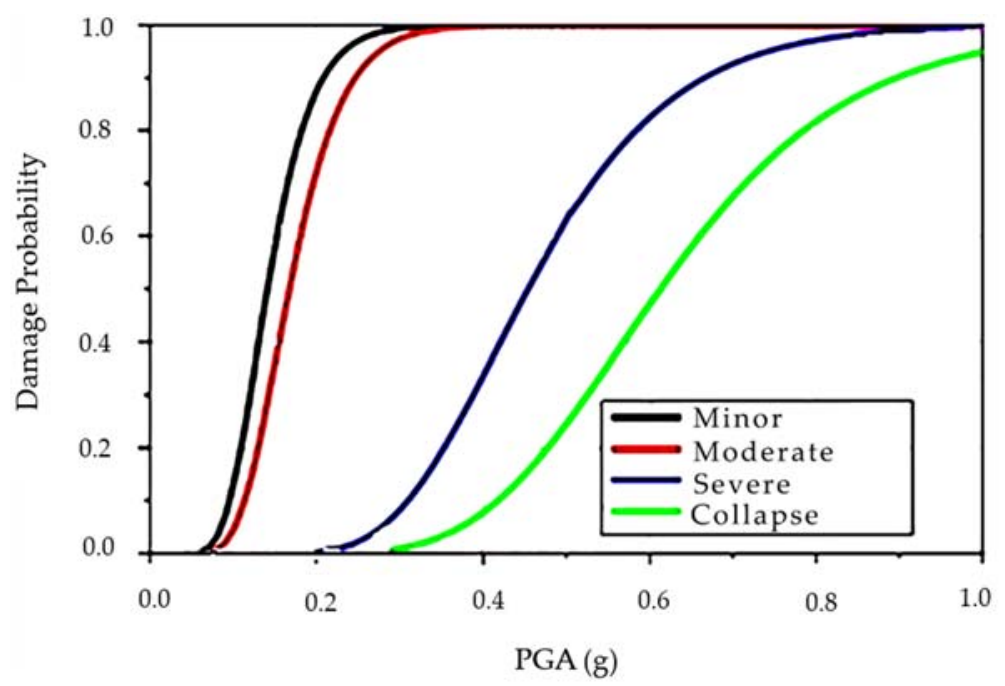

(a)

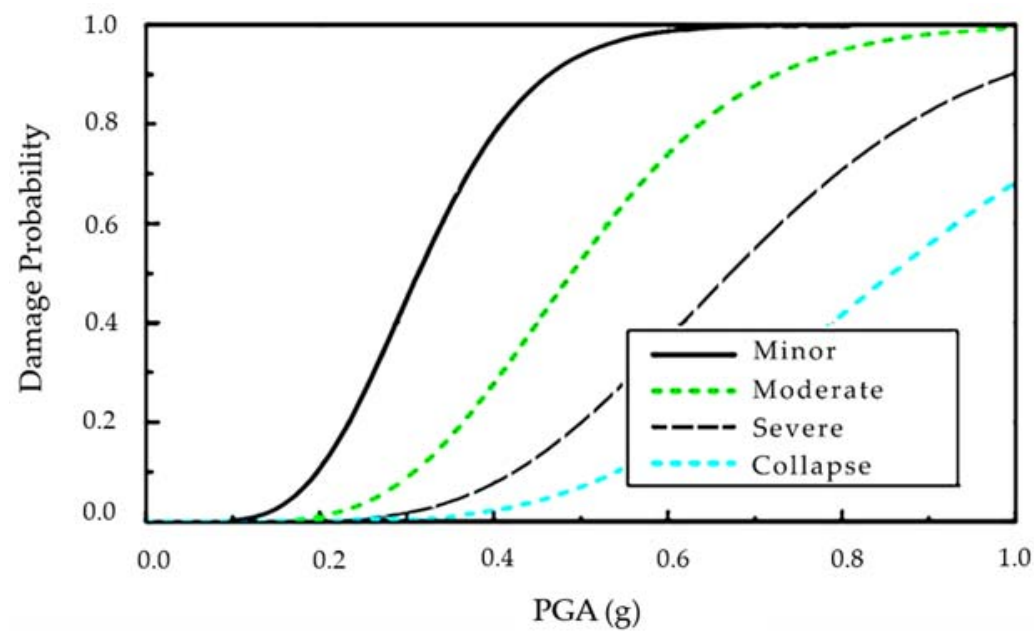

(b)

Figure 9. Comparison of the seismic fragility curves of (a) the isolated bridge and (b) the general bridge.

From Figure 9, under frequent earthquake action (PGA $=0.11 \mathrm{~g}$ ), the probability of minor damage and moderate damage to the general bridge were 18 and $6 \%$, respectively. The isolated bridge remained basically intact. Under rare earthquake action (PGA $=0.51 \mathrm{~g}$ ), the probability of serious damage to the general bridge was $68 \%$, and the probability of collapse $29 \%$, but the probability of minor damage, moderate damage, severe damage, and collapse of isolated bridges were $92,56,20$, and $10 \%$, respectively. Therefore, the probability of different damage states of the bridge structure was greatly reduced with the seismic isolation scheme. 


\section{Conclusions}

In this paper, an RC (reinforced concrete) isolated continuous girder bridge was selected as the research object. In order to reasonably evaluate the seismic performance of the isolated bridge, considering the randomness of the near-fault ground motion and structural parameters, an incremental dynamic analysis of the bridge structure under different failure states was carried out. With the copula function method, the joint distribution function of components was obtained, and the seismic fragility curve of the bridge system, considering the influence of multiple components and their demand correlation, was established, which was compared with the first-order limit reliability theory model. The main conclusions are as follows.

Compared with the traditional method, the copula function method has obvious advantages. It can not only overcome the limitation of the assumption that the seismic demands obey the lognormal distribution but can also describe the nonlinear correlation between the seismic demands on the bridge components, especially the tail correlation. This new method eliminates the limitation that only the Pearson correlation coefficient can describe linear correlation and thus simplifies the modeling process of the multivariate joint probability distribution function of the bridge structure. It provides a new model for the seismic vulnerability analysis of complex (multiple) bridge structures.

The fragility curve of bridge structures obtained with the copula method was located between the two limit values obtained with the first-order method, but there was still a large gap, which indicated that the limit error caused by the traditional fragility analysis method was relatively large. The calculation results showed that the failure probability of the whole bridge structure analyzed with the copula method had a smaller probability interval, and that the evaluation based on the copula method was more reasonable, safer, and more reliable, which also proved the calculation efficiency and superiority of the copula method.

Furthermore, in this study, the seismic fragility analysis of the isolated continuous girder bridge showed that the failure probability of the isolation bearing was relatively large and was more likely to occur as a limit state failure, while the failure probability of the pier was relatively small. Therefore, in the seismic design of this kind of isolated bridge structure, the seismic capacity of the isolation bearing should be the main consideration. At the same time, this study also showed that the probability of different failure states in the continuous bridge structure was greatly reduced with the seismic isolation scheme, which can greatly improve the seismic performance of the bridge.

Author Contributions: Conceptualization, investigation and writing, Q.L.; supervision, C.Y.; formal analysis, investigation and methodology, C.Y. All authors have read and agreed to the published version of the manuscript.

Funding: This research was supported by the Natural Scientific Research Foundation of Fujian, China (Grant No. 2021J01856).

Institutional Review Board Statement: Not applicable.

Informed Consent Statement: Not applicable.

Data Availability Statement: Not applicable.

Conflicts of Interest: The authors declare no conflict of interest.

\section{References}

1. Jangid, R.S.; Kelly, J.M. Base isolation for near-fault motions. Earthq. Eng. Struct. Dyn. 2001, 30, 691-707. [CrossRef]

2. Loh, C.H.; Wan, S.; Liao, W.I. Effects of hysteresis model on seismic demands: Consideration of near-fault ground motions. Struct. Des. Tall Build. 2002, 11, 155-169. [CrossRef]

3. Zhao, L.F.; Wei, D. Seismic analysis of RC frame structures subjected to near-fault pulse-like ground motions. Eng. Mech. 2005, 25, 150-193.

4. Yazdani, M.; Jahangiri, V.; Marefat, M.S. Seismic performance assessment of plain concrete arch bridges under near-field earthquakes using incremental dynamic analysis. Eng. Fail. Anal. 2019, 106, 104170. [CrossRef] 
5. Guo, A.; Yuan, W.; Lang, C.; Guan, X.; Li, H. Time-dependent seismic demand and fragility of deteriorating bridges for their residual service life. Bull. Earthq. Eng. 2015, 13, 2389-2409. [CrossRef]

6. Crespi, P.; Zucca, M.; Longarini, N.; Giordano, N. Seismic assessment of six typologies of existing RC bridges. Infrastructures 2020, 5, 52. [CrossRef]

7. Hameed, A.; Koo, M.-S.; Do, T.D.; Jeong, J.-H. Effect of lead rubber bearing characteristics on the response of seismic isolated bridges. KSCE J. Civ. Eng. 2008, 12, 187-196. [CrossRef]

8. Han, Q.; Du, X.I.; Liu, W.G. Shaking table test of isolated continuous girder bridge model under different earthquake intensity excitation. China J. Highw. Transp. 2008, 21, 50-56.

9. Ge, S.J.; Xiong, Z.H.; Zhai, M.G.; Pan, C.P. Research on seismic fragility of medium and small sized concrete continuous girder bridge. J. Highw. Transp. Res. Dev. 2013, 30, 60-65.

10. Kang, Q.; Huang, X.; Chen, J.; Zhou, L. Seismic response analysis of multi-span continuous isolated bridge. J. Earthq. Eng. Eng. Vib. 2014, 34, 217-223.

11. Ghosh, J.; Sood, P. Consideration of time-evolving capacity distributions and improved degradation models for seismic fragility assessment of aging highway bridges. Reliab. Eng. Syst. Saf. 2016, 154, 197-218. [CrossRef]

12. Billah, A.M.; Alam, M.S. Seismic fragility assessment of highway bridges: A state-of-the-art review. Struct. Infrastruct. Eng. 2015, 11, 804-832. [CrossRef]

13. Yang, D.X.; Li, G.; Cheng, G.D. Seismic analysis of base-isolated structures subjected to near-fault pulse like ground motions. J. Earthq. Eng. Eng. Vib. 2012, 3, 68-77.

14. Gautam, D.; Rupakhety, R.; Adhikari, R. Empirical fragility functions for Nepali highway bridges affected by the 2015 Gorkha Earthquake. Soil Dyn. Earthq. Eng. 2019, 126, 105778. [CrossRef]

15. Mosleh, A.; Jara, J.; Razzaghi, M.S.; Varum, H. Probabilistic Seismic Performance Analysis of RC Bridges. J. Earthq. Eng. 2018, 108, 1477637. [CrossRef]

16. Zhang, J.; Bi, K.; Zheng, S.; Jia, H.; Zhang, D.Y. Seismic system reliability analysis of bridges using the multiplicative dimensional reduction method. Struct. Infrastruct. Eng. 2018, 14, 1455-1469. [CrossRef]

17. Wu, W.P.; Li, L.F. System seismic fragility analysis methods for bridge structures. J. Vib. Shock 2018, 37, $273-280$.

18. Pan, Y.; Agrawak, A.K.; Ghosn, M. Seismic Fragility of continuous steel highway bridges in New York State. J. Bridge Eng. 2007, 12, 689-699. [CrossRef]

19. Simon, J.; Bracci, J.M.; Gardoni, P. Seismic response and fragility of deteriorated reinforced concrete bridges. J. Struct. Eng.—ASCE 2010, 136, 1273-1281. [CrossRef]

20. Kibboua, A.; Naili, M.; Benouar, D.; Kehila, F. Analytical fragility curves for typical Algerian reinforced concrete bridge piers. Struct. Eng. Mech. 2011, 39, 411-425. [CrossRef]

21. Choi, E.; DesRoches, R.; Nielson, B. Seismic fragility of typical bridges in moderate seismic zones. Eng. Struct. 2004, 26, 187-199. [CrossRef]

22. Tavares, D.H.; Suescun, J.R.; Paultre, P.; Padgett, J.E. Seismic fragility of a highway bridge in Quebec. J. Bridge Eng.—ASCE 2013, 18, 1131-1139. [CrossRef]

23. Nielson, B.G.; Des, R.R. Seismic fragility methodology for highway bridges using a component level approach. Earthq. Eng. Struct. Dyn. 2007, 36, 823-839. [CrossRef]

24. Wang, Q.A.; Wu, Z.Y.; Jia, Z.P. Multidimensional fragility analysis of bridge system under earthquake. Eng. Mech. 2013, 30, 192-198.

25. Shen, G.Y.; Yuan, W.C.; Pang, Y.T. Bridge seismic fragility analysis based on Nataf transformation. Eng. Mech. 2014, 31, 93-100.

26. Song, S.; Qian, Y.J.; Wu, G. Research on seismic fragility method of bridge system based on copula function. Eng. Mech. 2016, 33, 193-200.

27. Cornell, C.A.; Jalayer, F.; Hamburger, R.O.; Foutch, D.A. Probabilistic basis for 2000 SAC federal emergency management agency steel moment frame guideline. J. Struct. Eng. 2002, 128, 526-533. [CrossRef]

28. Vamvatsikos, D.; Cornell, C.A. Incremental dynamic analysis. Earthq. Eng. Struct. Dyn. 2002, 31, 491-514. [CrossRef]

29. Baker, J.W. Efficient analytical fragility function fitting using dynamic structural analysis. Earthq. Spectra 2015, 31, 579-599. [CrossRef]

30. Nelsen, R.B. An Introduction to Copulas; Springer Science and Business Media: New York, NY, USA, 2013.

31. Song, S.; Qian, Y.; Liu, J.; Xie, X.; Wu, G. Time-variant fragility analysis of the bridge system considering time-varying dependence among typical component seismic demands. Earthq. Eng. Eng. Vib. 2019, 18, 363-377. [CrossRef]

32. Mazzoni, S.; Mc, K.F.; Scott, M.; Fenves, G.L. The Open Sees Command Language Manual, Version 2.0; Pacific Earthquake Engineering Research Center, University of California at Berkeley: Berkeley, CA, USA, 2009.

33. Seo, J.; Linzell, D.G. Nonlinear seismic response and parametric examination of horizontally curved steel bridges using 3D computational models. J. Bridge Eng. 2013, 18, 220-231. [CrossRef]

34. Siqueira, G.H.; Sanda, A.S.; Paultre, P.; Padgett, J.E. Fragility curves for isolated bridges in Eastern Canada using experimental results. Eng. Struct. 2014, 74, 311-324. [CrossRef]

35. Mander, J.B.; Priestley, M.J.N.; Park, R. Observed stress-train behavior of confined concrete. J. Struct. Eng. 1988, 114, 1827-1849. [CrossRef] 
36. Qi, X.J.; Shen, Y.G. Uneven distribution of pounding effect in a curved grider bridge unden earthquake. J. Vib. Shock 2012, 31, 72-78.

37. Ghosh, J.; Padgett, J.E. Impact of multiple component deterioration and exposure conditions on seismic vulnerability of concrete bridges. Earthq. Struct. 2012, 3, 649-673. [CrossRef]

38. Park, C.; Kim, N.; Haftka, R. The effect of ignoring dependence between failure modes on evaluating system reliability. Struct. Multidiscip. Optim. 2015, 52, 251-268. [CrossRef]

39. Monteiro, R.; Delgado, R.; Pinho, R. Probabilistic seismic assessment of RC bridges: Part I-Uncertainty models. Structures 2016, 5, 258-273. [CrossRef]

40. Monteiro, R.; Zelaschi, C.; Silva, A.; Pinho, R. Derivation of fragility functions for seismic assessment of RC bridge portfolios using different intensity measures. J. Earthq. Eng. 2019, 23, 1678-1694. [CrossRef]

41. Faria, R.; Oliver, J.; Cervera, M. A strain-based plastic viscous-damage model for massive concrete structures. Int. J. Solids Struct. 1998, 35, 1533-1558. [CrossRef]

42. Park, Y.J.; Ang, A.H.S. Mechanistic seismic damage model for reinforced concrete. J. Struct. Eng. 1985, 111, 722-739. [CrossRef]

43. Lu, B.Y.; Liu, B.Q.; Liu, M.; Xing, G.H.; Wu, T. Quantitative research on reinforced concrete performance index of reinforced concrete bridge column. China J. Highw. Transp. 2010, 23, 49-57.

44. FEMA 356. Pre-Standard and Commentary for Seismic Rehabilitation of Buildings; American Society of Civil Engineers: Washington, DC, USA, 2000. 